\title{
Leprosy surveys in urban slums-possibilities for epidemiological investigations*
}

\author{
C R REVANKAR, B DUDHALKAR, \\ GIRIJA DEENU RAJU \& R GANAPATI \\ Bombay Leprosy Project, 6/27 Amar Bhuvan, Sion-East, Bombay \\ 400022, India
}

Received for publication 8 June 1981

\begin{abstract}
Summary Rapid industrialization and a population explosion in urban areas like Bombay have promoted the growth of a large number of slums where some $40 \%$ of the city's population is living in an overcrowded, unhygienic environment. This has led to many acute and chronic public health problems, one of the gravest of which is leprosy. Intensive surveys of 8 slums, in which 31,950 subjects were screened for leprosy, revealed a range of prevalence between 5.9 and $22.8 / 1,000$ with an average rate of $11.9 / 1,000$, thus indicating slums as hyperendemic foci. The average smear-positive case prevalence rate was $1.1 / 1,000$ and this shows a high quantum of infection in the slum communities. Contrary to general belief, these urban slums are stable in nature, housing a population coming from different parts of India. Various epidemiological investigations relating to leprosy under urban conditions therefore seem to be possible if our experience is indicative.
\end{abstract}

\section{Introduction}

Rapid industrialization and a constant influx of population into urban areas like Bombay, Calcutta and Madras have created environmental problems related to overcrowding, housing, water shortage, sewerage etc., leading in turn to a variety of public health problems in the form of diseases such as typhoid, infectious hepatitis, malaria, tuberculosis and leprosy. Since these problems could not be tackled on preventive grounds they are now acute and chronic. Leprosy has emerged as one of the major health problems in Bombay, where, in

*Presented at the XIth Biennial Conference of the Indian Association of Leprologists held at Madras, April 1979 
a population of 8 million people, it has been estimated that about $40 \%$ live in the slums of the city.

Earlier school surveys ${ }^{1}$ clearly pointed out the existence of endemic foci for leprosy in different parts of Bombay, especially in the northern suburbs, and it was thought that the source of infection in the community could be mostly in the slums. One subsequent study ${ }^{2}$ indicated the possibilities of subjecting slum dwellers to scientific screening for evidence of leprosy even under conditions prevailing in overpopulated cities such as Bombay. One such investigation ${ }^{3}$ showed the existence of a hyperendemic slum focus with a prevalence rate of smear-positive cases of 3/1,000. Based on these studies, the urgent need to survey these slum pockets in order to contain the infection was stressed, but further studies are necessary to collect epidemiologically significant data to plan effective public health measures against this disease. However, it is generally believed, wrongly, that the urban slum population is unstable and therefore unsuitable for epidemiological investigations. In this study we have attempted to collect data on slum dwellers, on place of origin, period of residence in slums etc., and relate these to prevalence rates of leprosy.

\section{Materials and methods}

Intensive house-to-house surveys were conducted for leprosy in 8 slums located in $\mathrm{H}$ and $\mathrm{T}$ wards of the Municipal Corporation of Greater Bombay. The surveys were done by trained and well-experienced paramedical workers. In 3 slums (Mount Mary, Khar-East, and Anandnagar) a special effort was made to collect data on place of origin, period of residence, etc. The data from these 8 slums were analysed for the present study.

\section{Results}

Table 1-5 show the information gained from the surveys, and the following points emerge:

Table 1: (i) Intensive examination of the population with a coverage of $81 \%$ was quite possible. (ii) In none of the slums was the prevalence rate less than $1 / 1,000$, at which level public health measures against leprosy should be implemented. ${ }^{4}$ (iii) The overall prevalence rate of $11.9 / 1,000$ is a clear indication of hyperendemicity. (iv) The prevalence rate of smear-positive cases ranged between 0.5 and 3/1,000 (mean 1.1/1,000) thus showing different levels of intensity of infection in these slum communities. 
Table 1. Prevalence rate (PR) of leprosy in different slums

\begin{tabular}{lcccccc}
\hline \multicolumn{1}{c}{ Slum } & $\begin{array}{c}\text { Enumerated } \\
\text { population }\end{array}$ & $\begin{array}{c}\text { Examined } \\
\text { population }\end{array}$ & $\begin{array}{c}\text { Total } \\
\text { cases }\end{array}$ & $\begin{array}{c}\text { PR/ } \\
1,000\end{array}$ & $\begin{array}{c}\text { Smear } \\
\text { +ve } \\
\text { cases }\end{array}$ & $\begin{array}{c}\text { PR of } \\
\text { +ve } \\
\text { cases }\end{array}$ \\
\hline $\begin{array}{l}\text { Danpada group } \\
\text { Ambedkar Road }\end{array}$ & 4,292 & 3,614 & 34 & 9.4 & 2 & 0.55 \\
KM Colony & 4,586 & 3,712 & 34 & 9.2 & 5 & 1.3 \\
Madlapada group & 3,925 & 3,248 & 74 & 22.8 & 10 & 3.0 \\
Kherwadi & 10,720 & 8,597 & 117 & 13.6 & 7 & 0.8 \\
Khar-East & 3,216 & 2,583 & 18 & 6.9 & 2 & 0.8 \\
Mount Mary & 4,703 & 3,803 & 36 & 9.5 & 5 & 1.3 \\
Khotwadi & 5,526 & 4,415 & 26 & 5.9 & 4 & 0.9 \\
Anandnagar & 2,377 & 1,978 & 43 & 21.7 & 1 & 0.5 \\
Totals & 39,345 & 31,950 & 382 & 11.95 & 36 & 1.1 \\
\hline
\end{tabular}

Table 2. Duration of residence of slum dwellers

\begin{tabular}{|c|c|c|c|}
\hline $\begin{array}{l}\text { Residence } \\
\text { (years) }\end{array}$ & $\begin{array}{l}\text { Population } \\
\text { enumerated }\end{array}$ & $\%$ & \\
\hline $0-5$ & 2,559 & 25 & \multirow{3}{*}{$75 \%$} \\
\hline $6-10$ & 2,210 & 221 & \\
\hline Over 11 & 5,427 & 53 & \\
\hline Totals & 10,196 & 100 & \\
\hline
\end{tabular}

Table 2: An analysis of the enumerated population of 10,196 living in 3 slums whose information on this aspect was available (Mount Mary, Khar-East and Anandnagar) showed that $75 \%$ of the inhabitants had been living in these slums for over 6 years, which can be considered as a criterion for stability of the population.

Table 3: (i) Analysis of 382 leprosy patients showed that 272 (71\%) had been living in the slums for over 11 years and 346 (90\%) for over 6 years. (ii) We were struck by the fact that $32(89 \%)$ smear-positive cases had lived in the slums for more than 11 years and $35(97 \%)$ over 6 years.

Table 4: (i) People from practically all the states of India were living in these slums. (ii) $34 \%$ of the 10,196 enumerated population came from the Ratnagiri district of Maharashtra state and 28\% from the remaining parts of the same state; $15 \%$ were from Uttar Pradesh. The remaining population came from other states. (iii) The overall prevalence of leprosy among those coming from various districts of Maharashtra was 16.2/1,000 (10.5/1,000 for those exclusively from Ratnagiri). The Uttar Pradesh group showed a prevalence rate of $7.4 / 1,000$.

More detailed analysis pertaining to 382 leprosy patients regarding their 
Table 3. Duration of residence of leprosy cases

\begin{tabular}{lccccc}
\hline $\begin{array}{c}\text { Residence } \\
\text { (years) }\end{array}$ & $\begin{array}{c}\text { Total } \\
\text { cases }\end{array}$ & $\%$ & $\begin{array}{c}\text { Smear } \\
+ \text { ve } \\
\text { cases }\end{array}$ & $\%$ \\
\hline $0-5$ & 36 & 10 & 1 & 3 & \\
$6-10$ & 74 & 19 & 90 & 3 & 8 \\
Over 11 & 272 & 71 & 92 & 89 & 97 \\
Totals & 382 & 100 & 36 & 100 \\
\hline
\end{tabular}

Table 4. Place of origin and prevalence rate (PR) of leprosy

\begin{tabular}{lcccc}
\hline \multicolumn{1}{c}{$\begin{array}{c}\text { Place of } \\
\text { origin of } \\
\text { population }\end{array}$} & $\begin{array}{c}\text { Enumerated } \\
\text { population }\end{array}$ & $\begin{array}{c}\text { Examined } \\
\text { population }\end{array}$ & Cases & PR/1,000 \\
\hline Ratnagiri district & $\begin{array}{l}3,509 \\
(34 \%)\end{array}$ & 2,199 & 23 & 10.5 \\
Other districts of & $\begin{array}{l}2,880 \\
(28 \%)\end{array}$ & 2,478 & 53 & 21.3 \\
Maharashtra & $\begin{array}{l}6,389 \\
(63 \%)\end{array}$ & 4,677 & 76 & 16.2 \\
Maharashtra State & $\begin{array}{l}1,490 \\
(15 \%)\end{array}$ & 1,084 & 8 & 7.4 \\
as a whole & $\begin{array}{l}2,317 \\
(22 \%)\end{array}$ & 2,016 & 13 & 6.4 \\
Uttar Pradesh & & & & \\
Other states & & & & \\
\hline
\end{tabular}

Table 5. Multiple case families

\begin{tabular}{ll}
\hline Families with leprosy cases & -321 \\
Multiple case families & -44 \\
& $(13.7 \%)$ \\
Families with associated & -16 \\
Smear-positive case & $(5 \%)$ \\
\hline
\end{tabular}

place of origin also showed that $94(25 \%)$ were from Ratnagiri district 46 (12\%) from Bombay proper. From Maharashtra as a whole there were 228 patients accounting for $60 \%$.

Table 5: (i) $13.7 \%$ of the families were associated with more than one case. (ii) $5 \%$ had a smear-positive case in the family.

\section{Discussion}

For the first time, figures on a large scale on the prevalence of leprosy in some of the slums in Bombay are available. All these figures clearly point out that these slums are hyperendemic for leprosy with a high quantum of infection in the slum community, for which not only the slum dwellers but also non-slum 
dwellers of all strata are constantly exposed. This stresses a need for an immediate implementation of public health measures to contain the infection.

This study also shows that the slums could be surveyed, with a minimum coverage of $80 \%$, with proper planning and employing trained paramedical teams.

The reason for variable prevalence rates in different slums could not be explained. One possible factor could be the varying genetic stock, since about $95 \%$ of the slum dwellers came from different states, where prevalence rates of leprosy are also variable. The prevalence rate among those from Ratnagiri was almost 10 times the estimated prevalence rate of $1.67 / 1,000$ in the district proper. ${ }^{5}$ A possible explanation could be that, due to low endemicity, the Ratnagiri population has no chance of developing natural immunity, and once they become exposed to a hyperendemic situation in Bombay they may be more likely to contract the disease. However, statistically planned immunoepidemiological studies on a larger scale in both Ratnagiri and Bombay may provide an explanation.

Contrary to the general belief, the urban slum population is stable, with minimal migration, so that long-term epidemiological studies can be undertaken easily.

The fact that $90 \%$ of the leprosy cases had been living in the slums for more than 6 years shows that some of them must have contracted the disease after their arrival. The period of residence of $97 \%$ of the smear positive cases for more than 6 years indicates their contribution towards the pool of infection in the community, and transmission of the disease.

The prevalence rates of deformities which were calculated for Mount Mary and Khar-East, 2.4 and 1.1/1,000 respectively, also helps to illustrate the overall gravity of the deformity problem in the slums, thus helping to plan a better service.

Many of the other factors related to the leprosy problem in slums are the subject of another study, which will be presented at a later date.

\section{Acknowledgement}

Our sincere thanks are due to Mr B K Rao for his secretarial assistance in preparing this article.

\section{References}

1 Ganapati R, Naik SS, Acharekar MY, Pade SS. Leprosy endemicity in Bombay - An assessment through surveys of municipal schools. Lepr Rev 1976; 47:127.

2 Ganapati R, Pandya SS, Nak SS, Dongre VV, D'Souza NGA. Assessment of school surveys as a method of case detection in an urban area endemic for leprosy. Ind $J$ Med Res 1977; 66: 732. 
$104 \quad C R$ Revankar et al.

3 Ganapati R, Girija D. Leprosy from urban angle. Bombay Hosp J 1979; 21 : 13.

4 WHO Expert Committee on Leprosy. 3rd report. Tech Report Sr 1966; No. 319.

Yellapurkar MV. Leprosy control programme in Maharashtra. NLO Newsletter 1980; 8: 101 . 